\title{
Serum erythropoietin levels in patients with central serous chorioretinopathy
}

This article was published in the following Dove Press journal:

Eye and Brain

5 June 2010

Number of times this article has been viewed

\author{
Burak Turgut' \\ Nevin Ilhan ${ }^{2}$ \\ Fatma Yayla Uyar' \\ Ulku Celiker' \\ Tamer Demir \\ Suleyman Serdar Koca ${ }^{3}$ \\ 'FIrat University School of Medicine, \\ Department of Ophthalmology, \\ Elazig, Turkey; ${ }^{2}$ Firat University \\ School of Medicine, Department of \\ Biochemistry, Elazig, Turkey; ${ }^{3}$ Firat \\ University School of Medicine, \\ Department of Interal Medicine, \\ Elazig, Turkey
}

Objective: To evaluate the levels of erythropoietin (EPO) in the serum in patients with central serous chorioretinopathy (CSC).

Methods: An institutional comperative clinical study. The serum EPO levels were measured with the enzyme-linked immunosorbent assay (ELISA) method, of 15 patients with active CSC (Group 1), 15 patients with inactive CSC (Group 2) and 15 healthy volunteers (Group 3). Kruskal-Wallis variance analysis and Mann-Whitney $U$ test were used for statistical analysis.

Results: The patient and control groups were matched for age and sex. There was no statistically significant variation with regard to age and gender among the groups $(P>0.05)$. The mean serum EPO concentrations in patients with active CSC (Group 1), inactive CSC (Group 2) and in healthy controls (Group 3) were $11.39 \pm 3.01 \mathrm{mlU} / \mathrm{mL}, 11.79 \pm 3.78 \mathrm{mlU} / \mathrm{mL}$ and $11.95 \pm 3.27 \mathrm{mlU} / \mathrm{mL}$, respectively. There was no significant variation among the serum EPO concentrations of the study groups $(P>0.05)$.

Conclusion: These findings suggest no role of serum EPO in pathogenesis of CSC.

Keywords: Central serous chorioretinopathy, erythropoietin, serum

\section{Introduction}

Central serous chorioretinopathy (CSC) is characterized by serous detachment of the neurosensory retina and/or the retinal pigment epithelium (RPE) frequently in the macular region. CSC is one of the ten most common diseases of the posterior segment of the eye. ${ }^{1}$ Although it is known to be a benign and self-limiting disease, in long-term follow-up, it has a recurrence rate of $30 \%$. Spontaneous resolution of serous retinal detachment is common in acute CSC with RPE changes. Recurrent or chronic detachment is often associated with more diffuse retina pigment epitheliopathy $(16 \%)$, which is resulting in RPE atrophy, macular degeneration, foveal atrophy and secondary subretinal neovascularization. Subsequently, it may cause persistent visual impairment. $^{2}$

The pathogenesis of CSC is unknown. However, it has been considered that the CSC may be due to focal RPE defect or choroidal lobular ischemia and choroidal venous congestion. ${ }^{3-5}$ Recent studies on CSC have shown the association of CSC with: psychological stress; type A personality; glucocorticoid treatment; endogenous hypercortisolism like Cushing's syndrome; systemic hypertension; and pregnancy. Thus, the increased levels of serum catecholamine, or glucocorticoid, or both, have been thought to play a role in the pathogenesis of CSC, in all these conditions. ${ }^{1,6-8}$
Correspondence: Burak Turgut Firat University School of Medicine, Department of Ophthalmology, Elazig, Turkey

Tel +90424233 3555

Fax +90 4242388096

Email drburakturgut@gmail.com 
Erythropoietin (EPO) is a glycoprotein hormone synthesized mainly by the kidney and also secreted by interstitial cells of the adrenal cortex, in response to tissue hypoxia. This cytokine is a hematopoietic growth factor that regulates red blood cell production by promoting survival, proliferation, and differentiation of erythroid progenitors in bone marrow. Erythropoietin has recently been shown to exhibit remarkable antioxidant and antiapoptotic effects on various cell types such as retinal neurons and RPE cells, besides its angiogenic activity on vascular endothelial cells. ${ }^{9}$ Recently it has been demonstrated that brain, retina, RPE, astrocytes and neurons have EPO receptors and that EPO has potent neuroprotective effects on brain and retina. ${ }^{10-13}$ Additionally, it has been demonstrated that EPO protects RPE cells from oxidative damage. ${ }^{1-20}$

Recent reports also demonstrated that some ocular diseases, such as diabetic retinopathy, glaucoma, diabetic macular edema and age-related macular degeneration, were associated with elevated EPO levels in serum, aqueous or vitreous. ${ }^{21-23}$ Because the EPO receptor is expressed on RPE cells and EPO has protective effects for RPE cells, we hypothesized that EPO might be related to the damage or the loss of RPE.

To the best of our knowledge, no previous studies have examined the possible relation between serum EPO and CSC. However, there is some evidence concerning the effects of $\mathrm{EPO}$ on the sympathetic system. Ksiazek et al reported that the recombinant human EPO treatment in the normotensive patients significantly increases the blood noradrenaline levels. ${ }^{24}$ In an experimental study, it was demonstrated that EPO has sympathetic hemodynamic effects. ${ }^{25}$ As hemodynamic effects of EPO and its potential interaction with the sympathetic system may suggest it plays a role in the pathogenesis of $\mathrm{CSC}$, we focused the possible relationship between EPO and catecholamines, which are reported to be increased in CSC. Identifying this possible relationship will provide important knowledge concerning the potential use of recombinant human EPO (rhEPO) or EPO antagonism in acute or recurrent CSC. We conducted this study to find out whether serum EPO plays a role in the pathogenesis and activity of CSC.

\section{Material and methods}

This pilot work was designed as a prospective case-control study and included 15 patients with active CSC (Group 1), 15 patients with inactive CSC (Group 2) and 15 age- and sex-matched healthy subjects (Group 3). The study was designed according to Helsinki Declaration and approved by the institutional ethics committee. Informed consents were obtained from the patients and the volunteers.

\section{Inclusion criteria}

Group 1: Patients with active CSC characterized by detachment of the neurosensorial retina caused by accumulation of serous fluid between the photoreceptor outer segments and the RPE in combination with monofocal or multifocal changes in the RPE documented by fundus fluorescein angiography (FFA) and optical coherence tomography (OCT). Group 2: Patients with inactive CSC defined by the retina being fully attached the presence of residual abnormalities of the RPE for more than 6 months documented by FFA and OCT. Group 3: Healthy subjects that are sex- and age-matched without exclusion criteria.

Potential candidates with kidney disease, diabetes mellitus, arteriosclerotic diseases (history of myocardial infarction, coronary artery disease, etc.), any hematologic disease (polycythemia vera, anemia, etc.), immune disease, or history of drug usage (chemotherapeutic agents, iron preparations, granulocyte colony-stimulating factor, zidovidine, etc.) that could influence the EPO level, were excluded from this study. Patients with previous laser surgery or history of intraocular surgery or intravitreal injection were also excluded.

\section{Blood analysis}

Venous blood samples $(5 \mathrm{~mL})$ were collected (without anticoagulant) from patients for measurement of the serum EPO concentration. The samples were centrifuged at $3000 \mathrm{rpm}$ for ten minutes after blood clotting, and the sera were analyzed immediately. The concentration of EPO in serum samples was measured by automated two-site sandwich immunoassay with chemiluminescent detection on an automated random access immunoassay analyser (IMMULITE 2000; Diagnostic Products Corporation, Los Angeles, CA) and using the IMMULITE 2000 EPO assay kit. This was the standard method for routine analysis of erythropoietin in our laboratory at the time of this study and was performed according to manufacturer's instructions. Values were expressed as $\mathrm{mIU} / \mathrm{mL}$. Manufacturer reference interval for serum EPO was 3.7-31.5 $\mathrm{mlU} / \mathrm{mL}$ according to the manufacturer's instruction.

\section{Statistical analysis}

Statistical analysis was performed using the Statistical Package for the Social Sciences (SPSS) version 11.0 (SPSS Inc., Chicago, IL, USA). Kruskal-Wallis variance analysis was used to evaluate the statistical significance of the age and EPO concentrations, which are nonparametric data among the groups (more than two: control, inactive CSC and 
active CSC). Subsequently, the posthoc Mann-Whitney $U$ test, was used to compare the significance of difference between to groups (control vs inactive CSC; control vs active $\mathrm{CSC}$; or inactive $\mathrm{CSC}$ vs active $\mathrm{CSC}$ ). The chi-square test was used to determine the significance of any difference between the groups for sex. Results were given as the means \pm standard deviations. $P$ value less than 0.05 was considered significant.

\section{Results}

Demographic data and the levels of EPO in the study groups are summarized in Table 1. The subjects included nine men $(60 \%)$ and six women (40\%) in Group 1, seven men (47.7\%) and eight women (53.3\%) in Group 2, nine men and six women in Group 3. The mean ages of the Group 1, Group 2 and Group 3 were: $30.67 \pm 4.10 ; 30.93 \pm 4.80$; and $31.40 \pm 4.32$ years, respectively. The patient and control groups were matched for age and sex and there was no statistically significant variation with regard to age and gender among the groups (Mann-Whitney $U$ test and chi-square test, $P>0.05$ ).

The mean serum EPO concentrations in patients with active CSC (Group 1), inactive CSC (Group 2) and in healthy controls (Group 3) were: 11.39 $\pm 3.01 ; 11.79 \pm 3.78$; and $11.95 \pm 3.27 \mathrm{mlU} / \mathrm{mL}$, respectively. There was no significant variation among the serum EPO concentrations of the study groups (Kruskal-Wallis variance analysis and Mann-Whitney $U$ test $P>0.05$ ).

\section{Discussion}

There are various theories about the pathogenesis of CSC. Potential factors playing a role in pathogenesis may include vitamin A deficiency, malnutrition, allergic reactions, toxic agents, phototoxic mechanisms, psychosomatic factors, glucocorticoid treatment, and endogenous hypercortisolism. ${ }^{1,26}$ Thus, some of these conditions, the increased levels of serum catecholamine or glucocorticoid or both have been thought to have a role in the pathogenesis of CSC.
The exact etiology of CSC is unknown and is probably multifactorial. However, it has been hypothesized that RPE cell loss plays an important role except choroidal vasospasm. ${ }^{4,5,27-30}$ This may be caused by RPE cells dying by apoptotic and nonapoptotic mechanisms. ${ }^{31,32}$ Recently, the EPO receptor has been expressed in RPE cells and the protective effects of EPO on retinal neurons and RPE cells has been demonstrated. ${ }^{33,34}$

Oxidative injury is thought to play an essential role in the degeneration, dysfunction, or loss of RPE cells and may be responsible for CSC..$^{35} \mathrm{EPO}$ might have a protective effect on RPE cells in various pathways against hypoxic, ischemic, apoptotic, and necrotic stress, including the inhibition of apoptosis, restoration of vascular autoregulation, attenuation of inflammatory responses, and antioxidant properties. ${ }^{13,19,36-38}$

In the previous studies it has been suggested that CSC has been caused by intravenous epinephrine in the experimental monkey model. It has also been considered that the misdirection of the ion pump due to the alteration of intracellular cAMP level in RPE cells by $\beta$ adrenergic stimulation, might cause CSC. ${ }^{39}$ Additionally, Yannuzzi considered that Type A personality might be strongly associated with the sympathetic release in CSC and that macula was the target tissue for this pathology. ${ }^{1}$ In recent studies, it has been reported that EPO treatment is associated with hypertension and increased sensitivity to sympathetic stimuli. ${ }^{40-43}$

Although there is no data about the relationship between CSC and EPO, some evidence concerning with the effects of EPO on the sympathetic system is available. In an experimental study, it has been demonstrated that EPO has sympathetic hemodynamic effects. ${ }^{29}$ Ksiazek et al have reported that the rhEPO treatment in the normotensive patients significantly increases the blood noradrenaline levels. ${ }^{24}$

To the best of our knowledge, this is the first report investigating the association between serum EPO level and CSC. In this study we expected that there would be an

Table I The demographic data and the levels of erythropoietin (EPO) in the study groups

\begin{tabular}{|c|c|c|c|}
\hline & \multicolumn{2}{|c|}{ Central serous chorioretinopathy } & \multirow{2}{*}{$\begin{array}{l}\text { Healthy controls } \\
(N=15)\end{array}$} \\
\hline & Active $(\mathrm{N}=15)$ & Inactive $(N=15)$ & \\
\hline \multirow[t]{2}{*}{ Age (years) } & $30.67 \pm 4.10$ & $30.93 \pm 4.80$ & $31.40 \pm 4.32$ \\
\hline & (range: 24-38) & (range: $24-40$ ) & (range: $25-40$ ) \\
\hline \multirow[t]{2}{*}{ Gender (\%) } & 9 males $(60 \%) /$ & 7 males $(46.7 \%) /$ & 9 males $(60 \%) /$ \\
\hline & 6 females $(40 \%)$ & 8 females (53.3\%) & 6 females $(40 \%)$ \\
\hline $\mathrm{EPO}(\mathrm{mU} / \mathrm{mL})$ & $11.39 \pm 3.01$ & $11.79 \pm 3.78$ & $11.95 \pm 3.27$ \\
\hline
\end{tabular}


elevation or depression in the EPO level in serum taken from patients (especially those with active CSC). Our rationale was based on the following: 1) It has been known that exogenic EPO administration in experimental models has shown sympathetic effects, we therefore considered that EPO levels could be increased; 2) as EPO is a neuroprotective cytokine for RPE cells we alternatively thought that levels could be decreased.

In fact serum EPO levels were not found to vary significantly between patients and controls. These results may suggest that serum EPO levels do not alter in patients with CSC. Although our results do not confirm any significant alteration in serum EPO concentration in patients with CSC, it is possible that EPO may play a role in the pathophysiology of CSC because it has various effects such as antiapoptotic, antioxidant, anti-inflammatory and neuroprotective and also sympathetic hemodynamic effects. The assessment of the EPO levels in aqueous or vitreous humor in the patients with CSC could provide more valuable knowledge.

Additionally, EPO function may be modulated by the ratio between free and bound EPO, by the expression of different forms of the receptors, the ratio between signaling and nonsignaling receptors, and the presence of specific inhibitors. These factors have to be taken into account to evaluate the possible role of EPO in CSC.

The present study may have been limited in that catecholamines, which might associate with CSC, were not evaluated. This assessment is difficult because the levels of these hormones may be easily affected by various factors and situations.

In conclusion, the results of this pilot study suggest that there is no role of serum EPO on RPE defects, choroidal vascular dysregulation, and thus in the pathogenesis of CSC. Further studies are needed to know more about molecular regulation and effects of EPO, to investigate the levels of free and bound EPO, and to determine EPO's role in the pathogenesis of CSC.

\section{Acknowledgments}

Involved in the conduct of study (BT, FYU, NI); collection of data, typing and editing of manuscript; statistical analysis and editing of manuscript (BT, SSK) and preparation, review, or approval of the final manuscript (BT, NI, FYU, UC, TD, SSK).

\section{Disclosure}

The authors report no conflict of interest in this work.

\section{References}

1. Yannuzzi LA. Type A behavior and central serous chorioretinopathy. Retina. 1987;7:111-131.

2. Castro-Correia J, Countinho MF, Rosas V, et al. Long-term follow-up of central serous retinopathy in 150 patients. Doc Ophthalmol. 1992;81:379-386.

3. Hayashi K, Hasegawa Y, Tokoro, T. Indocyanine green angiography of central serous chorioretinopathy. Int Ophthalmol. 1986;9:37-41.

4. Prunte C, Flammer J. Choroidal capillary and venous congestion in central serous chorioretinopathy. Am J Ophthalmol. 1996;121:26-34.

5. Scheider A, Naseman JE, Lund OE. Fluorescein and indocyanine gren angiographies of central serous choriodopathy by scanning laser ophthalmoscopy. Am J Ophthalmol. 1993;115:50-65.

6. Haimovici R, Rumelt S, Melby J. Endocrine abnormalities in patients with central serous chorioretinopathy. Ophthalmology. 2003;110:698-703.

7. Eckstein MB, Spalton DJ, Holder G. Visual loss from central serous retinopathy in systemic lupus erythematosus. $\mathrm{Br} J$ Ophthalmol. 1993;77:607-609.

8. Bouzas EA, Karadimas P, Pournaras CJ. Central serous chorioretinopathy and glucocorticoids. Surv Ophthalmol. 2002;47:431-448.

9. Wang ZY, Shen LJ, Tu L, et al. Erythropoietin protects retinal pigment epithelial cells from oxidative damage. Free Radic Biol Med. 2009; 46:1032-1041.

10. Becerra SP, Amaral J. Erythropoietin: an endogenous retinal survival factor. N Engl J Med. 2002;347:1968-1970.

11. Fisher JW. Erythropoietin: physiology and pharmacology update. Exp Biol Med. 2003;228:1-14.

12. Jelkmann W. Effects of erythropoietin on brain function. Curr Pharm Biotechnol. 2005;6:65-79.

13. Watanabe D, Suzuma K, Matsui S, et al. Neuroprotective effects of erythropoietin on glutamate and nitric oxide toxicity in primary cultured retinal ganglion cells. Brain Res. 2005;1050:15-26.

14. Kim KH, Oudit GY, Backx PH. Erythropoietin protects against doxorubicin induced cardiomyopathy via a PI3K-dependent pathway. J Pharmacol Exp Ther. 2008;324:160-169.

15. Katavetin P, Tungsanga K, Eiam-Ong S, et al. Antioxidative effects of erythropoietin. Kidney Int Suppl. 2007;107:10-15.

16. Kilic U, Kilic E, Soliz J, et al. Erythropoietin protects from axotomyinduced degeneration of retinal ganglion cells by activating ERK-1/-2. FASEB J. 2005;19:249-251.

17. Zhong L, Bradley J, Schubert W, et al. Erythropoietin promotes survival of retinal ganglion cells in DBA/2J glaucoma mice. Invest Ophthalmol Visu Sci. 2007;48:1212-1218.

18. Tsai JC, Wu L, Worgul B, et al. Intravitreal administration of erythropoietin and preservation of retinal ganglion cells in an experimental rat model of glaucoma. Curr Eye Res. 2005;30:1025-1031.

19. Yamasaki M, Mishima HK, Yamashita H, et al. Neuroprotective effects of erythropoietin on glutamate and nitric oxide toxicity in primary cultured retinal ganglion cells. Brain Res. 2005; 1050:15-26.

20. García-Ramírez M, Hernández C, and Simó R. Expression oferythropoietin and its receptor in the human retina: a comparative study of diabetic and non-diabetic subjects. Diabetes Care. 2008;31:1189-1194.

21. Inomata $Y$, Hirata A, Takahashi E, et al. Elevated erythropoietin in vitreous with ischemic retinal diseases. Neuroreport. 2004;15: 877-879.

22. Katsura Y, Okano T, Matsuno K, et al. Erythropoietin is highly elevated in vitreous fluid of patients with proliferative diabetic retinopathy. Diabetes Care. 2005;28:2252-2254.

23. Cumurcu T, Bulut Y, Demir HD, et al. Aqueous humor erythropoietin levels in patients with primary open-angle glaucoma. $J$ Glaucoma. 2007;16:645-648.

24. Ksiazek A, Zaluska WT, Ksiazek P. Effect of recombinant human erythropoietin on adrenergic activity in normotensive hemodialysis patients. Clin Nephrol. 2001;56:104-110. 
25. Kristensen J, Soegaard H, Maeng M, et al. Acute haemodynamic effects of erythropoietin alone and in combination with dopamine in a porcine model. Clin Physiol Funct Imaging. 2006;26:283-287.

26. Gass JDM. Central serous chorioretinopathy and white subretinal exudation during pregnancy. Arch Ophthalmol. 1991;109:677-681.

27. Miceli MV, Liles MR, Newsome DA. Evaluation of oxidative processes in human pigment epithelial cells associated with retinal outer segment phagocytosis. Exp Cell Res. 1994;214:242-249.

28. Sparrow JR, Zhou J, Ben-Shabat S, et al. Involvement of oxidative mechanisms in blue-light-induced damage to A2E-laden RPE. Invest Ophthalmol Vis Sci. 2002;43:1222-1227.

29. Haefeli WE, Bargetzi MJ, Starnes HF, et al. Evidence for activation of the sympathetic nervous system by recombinant human interleukin-1 beta in humans. J Immunother Emphasis Tumor Immunol. 1993;13: 136-140.

30. Iida T, Kishi S, Hagimura N, et al. Persistent and bilateral choroidal vascular abnormalities in central serous chorioretinopathy. Retina. 1999; 19:508-512.

31. Dunaief JL, Dentchev T, Ying GS, et al. The role of apoptosis in age related macular degeneration. Arch Ophthalmol. 2002;120: 1435-1442.

32. Ambati J, Ambati BK, Yoo SH, et al. Age-related macular degeneration: etiology, pathogenesis, and therapeutic strategies. Surv Ophthalmol. 2003;48:257-293.

33. Celik M, Gökmen N, Erbayraktar S, et al. Erythropoietin prevents motor neuron apoptosis and neurologic disability in experimental spinal cord ischemic injury. Proc Natl Acad Sci US A. 2002;99:2258-2263.
34. Juul SE, Joyce AE, Zhao Y, et al. Why is erythropoietin present in human milk? Studies of erythropoietin receptors on enterocytes of human and rat neonates. Pediatr Res. 1999;46:263-268.

35. Cai J, Nelson KC, Wu M, et al. Oxidative damage and protection of the RPE. Prog Retin Eye Res. 2000;19:205-221.

36. Brines M, Grasso G, Fiordaliso F, et al. Erythropoietin mediates tissue protection through an erythropoietin and common B-subunit heteroreceptor. Proc Natl Acad Sci U S A. 2004;101:14907-14912.

37. Grasso G, Sfacteria A, Cerami A, et al. Erythropoietin as a tissueprotective cytokine in brain injury: what do we know and where do we go? Neuroscientist. 2004;10:93-98.

38. Fisher JW. Erythropoietin: physiology and pharmacology update. Exp Biol Med. 2003;228:1-14.

39. Spitznas M. Pathogenesis of central serous retinopathy: a new working hypothesis. Graefe's Arch Clin Exp Ophthalmol. 1986;224:321-324.

40. Smith KJ, Bleyer AJ, Little WC, et al. The cardiovascular effects of erythropoietin. Cardiovasc Res. 2003;59:538-548.

41. Buemi M, Allegra A, Aloisi C, et al. Hemodynamic effects of recombinant human erythropoietin. Nephron. 1999;81:1-4.

42. Hand MF, Haynes WG, Johnstone HA, et al. Erythropoietin enhances vascular responsiveness to norepinephrine in renal failure. Kidney Int. 1995;48:806-813.

43. Akimoto T, Kusano E, Fujita N, et al. Erythropoietin modulates angiotensin II- or noradrenaline-induced $\mathrm{Ca}(2+)$ mobilization in cultured rat vascular smooth-muscle cells. Nephrol Dial Transplant. 2001; $16: 491-499$.
Eye and Brain

\section{Publish your work in this journal}

Eye and Brain is an international, peer-reviewed, open access journal focusing on clinical and experimental research in the field of neuro-ophthalmology. All aspects of patient care are addressed within the journal as well as basic research. Papers covering original research, basic science, clinical and epidemiological studies, reviews and evaluations, guidelines, expert opinion and commentary, case reports and extended reports are welcome. The manuscript management system is completely online and includes a very quick and fair peer-review system, which is all easy to use. Visit http://www.dovepress.com/ testimonials.php to read real quotes from published authors. 